\title{
Cognition of Metaphorical Text in President Muhammadu Buhari's Inaugural Speech
}

\author{
Eniayo Sobola \\ University of Lagos, Nigeria
}

\begin{abstract}
Political discourse has gained prominence in Nigeria and a crop of literature has emerged from different fields of study to discuss how the discourse has presented issues prevalent in the country at different political epochs. Political discourse uses figurative language such as metaphor, simile, metonymy, paradox, irony and antithesis. The use of figurative language raises issues on interpretation and cognition of political discourse. This study investigates cognition of metaphors used by President Muhammadu Buhari in his inaugural speech on his assumption of office as the president of Nigeria on 29th May, 2015, which was identified as
\end{abstract}

\footnotetext{
Eniayo Sobola

Lecturer, Department of English, University of Lagos, Nigeria

Email: sobolaeniayo@gmail.com
}

Received 17 May, 2020; Revised 8 July, 2020; Accepted 19 August, 2020

Copyright (C) 2020 Language Research Institute, Sejong University Journal of Universal Language is an Open Access Journal. All articles are distributed online under the terms of the Creative Commons Attribution Non-Commercial License (http://creativecommons.org/licenses/by-nc/3.0) which permits unrestricted non-commercial use, distribution, and reproduction in any medium, provided the original work is properly cited. 
data and collected through media monitoring. Theory of lexical concept and cognitive model (LCCM) propounded by Vyvyan Evans was employed for analysis. The study concludes that metaphors are used in political discourse to encode ideological belief; interpretation of ideological views in the metaphorical text contributes towards cognition of the metaphor in political discourse; a metaphor is an embodiment of ideologies which could not be easily interpreted in a literal sense; linguistic contents in the metaphor and their relationships contribute towards interpretation and cognition of metaphors, and metaphors in Nigerian political discourse address Nigerian contemporary political issues.

Keywords: political discourse, metaphor, cognition, inaugural speech, text, ideology

\section{Introduction}

Political discourse has been an effective tool in the hand of political actors used for handling of sensitive political issues in society (Sobola 2013). Political administration cannot be successful without meticulous coordination of political discourse to coax the societal populace to take cognisance of the sentiment of government of the day. Language is used by political actors to arouse emotions and passions in their target audience in order to convince them to accept their sentiment and ideological view on a political issue (Opeibi 2018). This persuasion is not done without application of rhetorical device like metaphor which helps in composition of ideological views. It is no doubt that language in general is germane towards achieving political aim and effective administration in social settings. Salamini (1981) has emphasised that no one can engage in politics without effective use of language because language is instrumental to factual presentation of political ideologies. Wilson 
(2001) corroborates the earlier statement by Salamini by making a claim that the totality of political discourse analysis is to decipher how language is manipulated towards achieving certain political effects. Manipulation of language to achieve political effects is done through inaugural speech composition and presentation. Inaugural speech which is the major focus of this study is a special political discourse that political heads of countries must give after assuming the office. This speech reflects vision, mission and intention of the political head of state in the new administration. It is a pointer to the ideology that is set in motion for the new government. Irrespective of the ideology employed in the speech, the speech must focus on the benefits of the new government to the citizenry. The major political effect of political discourse in Nigeria is strengthening the cord that binds different ethnic groups in the nation together. This has been observed in Nigerian political discourse since its inception in 1922 when political parties came into operation in the country (Sobola 2013), and it is still the focus of every sincere government in power. This is achieved through the machinery of language because language is imbued with the potency of influencing the people's worldview in order to affect their society (Opeibi 2007). Therefore, language is used by political actors to woo the citizens to accept their views. This has been practised by many presidents and heads of state in Nigeria.

\section{Data}

Political discourse, which serves as data for this study, could be described as the heart of democracy in every society which determines the influence of political actors on the electorate. 
Political discourse is simply the discourse in political context. It is contextualized in the political domain (van Dijk 1997). It could be culturally and historically determined as an outcome of politics (Bayram 2010). Political discourse is the technique of decision making in democratic society. It is seen as a tool used to sift opinions, views and ideas in order to discover the action that would be able to solve societal problems. Johnson \& Johnson (2000: 292) assert that:

The purpose of political discourse includes clarifying citizen's understanding of the issue, helping citizens reach their best reasoned judgement as to which course of action will solve a problem, increasing citizens participation in the political process, and socializing the next generation into the procedures and attitudes they need to be active citizens.

If the citizens are well enlightened on the socio-political issues in their society through political discourse, then we would realise that political discourse is essential for maintenance of a peaceful society. There are many conflicting issues that are generated in society. The purpose of political discourse is to resolve those issues through reasoned views. Opeibi (2005) explains that the linguistic composition of political discourse is deliberate because it is delicately structured to establish and manage social relationships. Beard (2000) is in consonance with Opeibi that politicians carefully construct their language to seek approval of people in order to gain power and to retain it. Politicians use language to persuade their audience to accept their political claims as being valid (Osoba 2014, 2018). A politician is only successful when he is able to use his knowledge of formal influence to make people accept his claim and ideology 
through his discourse (Edelman 1977).

Political cognition is the process involved in the interpretation of political discourse. It is the mental representation such as knowledge and opinions about political actors, parties and political activities shared by individuals in a political setting. It is based on the context of situation because it takes into cognisance all activities and events that surround a political discourse. It is based on the background knowledge shared by people based on political events in their society. This knowledge is required in the cognitive process involved in the comprehension of the form of language use in political discourse. Political cognition could further be referred to as understanding of the mental processes involved in the interpretation of discourse in political context. van Dijk (2008) asserts that context should not be seen as an objective situation based on social construct, but a subjective construct of the participants based on the relevant properties of the situation. The subjective construct projects a mental model through which the context is determined. The mental model constructed by the participants in discourse is premised upon the context of discourse. van Dijk (2008) proposes a theory of context models as "a special kind of everyday experience model, represented in the episodic memory of discourse participants" (p. 56). By implication, cognitive models are based on the context of discourse, that is, the situation constructed by the participants in discourse (Hernández 2009). It is presumed that context models determined the production and understanding of discourse. Text and talk cannot be fully understood without identification of the appropriate models in the discourse context, which help in the interpretation and cognition of the text and talk (Solomon-Etefia 2018). This approach posits that language users are active in constructing their subjective interpretation of the existing communicative situation. Understanding 
the context of discourse is based on cognition of the models inherent in the text of the discourse (Boubekri 2019).

Political discourse has been a tool for national unity in Nigeria as many presidents and heads of states in Nigeria have employed it to coordinate peaceful co-existence of Nigerians with social and cultural diversities (Sobola 2013). It is evident in Nigerian sociopolitical context that political discourse should be persuasive because it has been constantly used to woo the electorate during election periods and also to win their cooperation for successful administration. This is possible because the figurative tropes employed in the composition of their discourse are not difficult for the audience to comprehend. Opeibi (2005) asserts that political actors use their language carefully to communicate their intended messages, seek approval, support and sympathy of people to gain, control and retain power. All these characterised political discourse in Nigeria.

A lot of creativities are employed in political language in spite of its organised structure. Müller (2005) asserts that political speeches constitute a domain of political creativity. Political speech is not just persuasive or rhetorical, but it is creative and shares some features with literary creativity one of which is metaphor.

In the context of this study, metaphor could be described as meaning transfer or semantic shift (Sobola 2019) where an expression is used to conceptualise an ideology with an implicit comparison. Fromkin et al. (2003) explain that metaphor is an essential part of semantics without which our ability to communicate effectively and efficiently would be affected. Thus, they imply that understanding of metaphor aids effective communication as figurative use of language requires special attention in its interpretation so that it will not generate the meaning outside the context of its usage. Metaphor is 
viewed as an important aspect of language creativity. It is anomalous to interpret a metaphorical statement literally because metaphor is meaningful outside the literal context. Metaphor has a strong cultural component (Park 2009), and it is best understood in a cultural context. Fromkin et al. (2003) thus conclude that metaphorical language is the highest level of language creativity.

Some scholarly works have been done on the use of metaphor in various fields. Opeibi (2009) examines the use of metaphors as persuasive techniques in political discourse. His study shows that metaphor could be seen as the figure of transportation, where tenor is the idea meant to be conveyed and vehicle is the image or form in which the metaphor appears. Opeibi further describes the linguistic characteristics of metaphors under three criteria: reification, which is a reference to something abstract by using a word or phrase in a concrete context; personification, which is a reference to an inanimate object using a word or phrase in an animate context; and de-personification, which is a reference to something animate using a word or phrase in inanimate context. In the study, metaphors in political contexts are categorised into metaphors of journey, metaphors of food, metaphors of religion, metaphors of sports and war, and metaphors of time. Müller (2005) explicates the role of creative metaphors in political discourse using Swiss political speeches. The strategic use of creative metaphors in political speeches was explored in the study to show a relationship between political speeches and literature. The study concludes that both political speeches and literature employ linguistic creativity which is a form of deviation from normal language use, but deviation in political speeches is more constrained than that of literature. These studies establish the purpose of linguistic creativity in political discourse, especially metaphor, but they still leave the gap in the area of interpretation and cognition of metaphors used in political 
discourse. Cognition of metaphors paves a ground for their interpretation through which ideologies couched in the metaphorical expression are deciphered. Understanding of these ideologies through lexical concepts in the metaphors aids their interpretation.

\section{Theory of Lexical Concept and Cognitive Model}

The theory of Lexical Concept and Cognitive Model (LCCM) was propounded by Vyvyan Evans (2006, 2009a, 2009b, 2010b, 2013a, $2013 b$ ) as a theoretical model for an analysis of figurative language, especially metaphor and metonymy. The theory was built to account for linguistic features of figurative language, which was believed that the $\mathrm{CMT}^{1}$ of Lakoff \& Johnson (1980) could not account for. The CMT accounts for conceptual mapping in the target and the source domains to examine the features common to both domains. LCCM theory accounts for lexical representation and semantic composition. It is based on the lexical approach to meaning construction. It also accounts for semantic change in language use, and at the same time revealing psychological reality.

According to the theory, meaning should be seen as a process or an act, and that meaning is derived from how words are used in utterances, that is, how they activate and depict conceptual knowledge. It is also concerned with how the speaker composed his knowledge to communicate his intention.

\footnotetext{
1 The following abbreviations are used in this paper: CMT (conceptual metaphor theory), LCCM (lexical concept and cognitive model).
} 


\subsection{Lexical Concept Integration}

In lexical concept integration, the semantic potential of the lexical concepts subjected to matching is identified and the particular features of the two lexical concepts that help in realising the linguistic meaning are linked through the process of matching. Lexical concept integration is guided by processes. It involves the process of integrating linguistic content in the lexical concept in order to activate their conceptual content. The process helps in construction of meaning by producing a semantic value of the lexical concepts. A lexical concept activates access to various cognitive models which are linked to other cognitive models. A lexical concept expedites access to a cognitive model profile, which is also known as semantic potential. The cognitive model profile is the extent to which a lexical concept activates access to either directly or indirectly (Evans 2013b). The cognitive models to which a lexical concept allows access directly are primary cognitive models while those that are indirectly accessed are secondary cognitive models. The secondary cognitive models are profile for one of the primary cognitive models.

Matching can only take place when open-class lexical concepts in the lexical conceptual unit activate part(s) of the conceptual content they expedite access to. The part of semantic potential that is activated is constrained by the nature of semantic value, that is, the meaning expected from integration. Integration, which is the opening of linguistic content for activation, is followed by interpretation, which is the activation of conceptual content.

The open-class lexical concepts only can undergo interpretation process in a lexical conceptual unit. A successful interpretation enables the open-class lexical concepts to achieve informational characterisation, which is semantic interpretation. This is achieved 
when relevant parts of semantic potential which the lexical concepts facilitate access to are activated (Evans 2010a).

Each of the cognitive models from the open-class lexical concepts in the lexical conceptual unit is an interpretation. The main purpose of matching is to bring out the interpretation that is produced by linking the appropriate cognitive models from the lexical concepts chosen in the conceptual lexical unit. As soon as matching takes place between one or more cognitive models in the cognitive model profiles associated with relevant lexical concepts, interpretation then takes place. The interpretation generates the required meaning. For example, the interpretation of 'Nigeria is blessed' is demonstrated below according to Evans' modelling (Figure 1).

Figure 1. Matching for 'Nigeria is blessed'

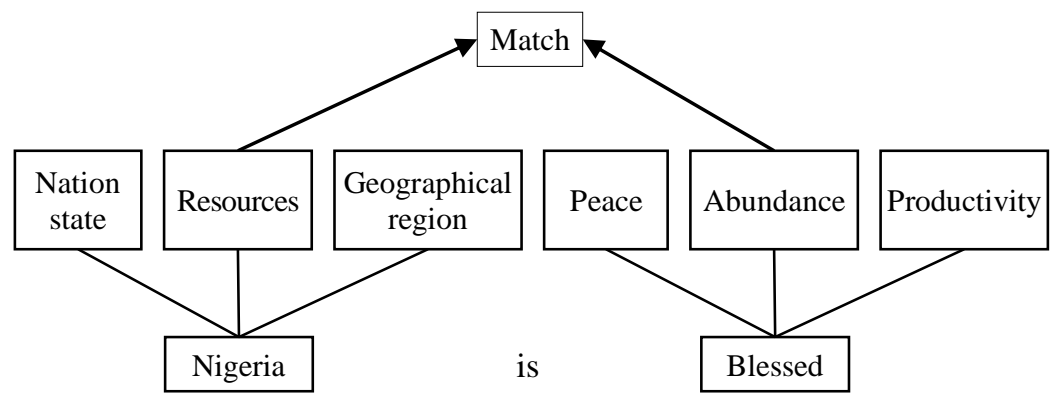

Matching is guided by two basic principles: principle of conceptual coherence and principle of schematic coherence. According to the principle of conceptual coherence, matching occurs between one or more cognitive models which belong to different cognitive model profiles. It means that models in the same cognitive model profile could not be matched. This principle depends on the second 
principle, the principle of schematic coherence which states that the conceptual content associated with entities, participants and the relations between them must exhibit coherence in fusion (Evans 2010a). The two principles ensure that matching takes place only when the cognitive models that undergo matching are from different cognitive model profiles, and they are accessed by different lexical concepts, and at the same time, they must portray coherence in fusion.

A search is conducted in the primary cognitive model profiles of two lexical concepts subjected to matching before matching can be done. Failure to attain matching in the primary domain leads to establishing a new search domain in the secondary cognitive model profile. The new search is meant to identify the cognitive models in the secondary cognitive model profile, out of which a model is matched to another model that attains coherence with it in another lexical concept subject to matching.

\section{Methodology}

Social and digital technologies have contributed a lot to methodology in political and democratic practices through their efforts in promoting and propagating political ideologies (Opeibi 2018). The source of data is President Muhammadu Buhari's inaugural speech delivered on 29th May, 2015, which has been uploaded on the internet. Media monitoring process is applied to source the data online. From the outcome of the search, The Guardian online newspaper is selected and the written form of the speech is downloaded. The speech is examined to identify the possible metaphors used in it. The sample metaphors are extracted and processed for analysis. Analysis is done through the lexical 
concept integration in the theory of LCCM discussed above.

\section{Presentation of Sample Metaphors}

Data samples to be analysed are presented below.

I thank our other countrymen and women who did not vote for us but contributed to make our democratic culture truly competitive, strong and definitive.

These fears are groundless.

The past is prologue.

What is now required is to build on these legacies

our chosen route to national development is democracy

the federal government should not fold its arms and close its eyes

Data sample extracted from The Guardian "President Buhari's Inaugural Speech" (Buhari 2015).

\section{Data Analysis}

Analysis of data is done on the metaphorical text in the speech by applying LCCM theory to demonstrate the process involved in cognition of metaphors.

\subsection{Thank our other Countrymen and Women who Did not Vote for us but Contributed ...}

The ideological belief expressed in the metaphorical text, who did 
not vote for us but contributed, is that "vote" and "contribution" are lexical concepts with cognitive models that express the understanding of voting in form of a contribution. The lexical concept "vote" instantiates three ideological models-election, power, free-at the primary level. The ideological view is that voting is a process of election; voting stands as the power of electorate to choose their representatives, and voting should be free and fair. The lexical concept "contribution" instantiates three ideological modelscompulsory, resources, voluntary-at the primary level. The ideological view is that contribution may be compulsory, where every member of a group is compelled to make contributions; contribution provides resources-either financial or material or human - that are essential for any successful administration, and contribution could be voluntary, where the contributors willingly make their contributions without being coerced.

Marching that is supposed to link the two concepts could not take place at the primary level because the appropriate models suitable for matching could not be identified at the primary level. Therefore, there is a need to initiate a secondary cognitive model profile for a model in each of the two concepts. The model "power" in the lexical concept "vote" is selected, and it instantiates three ideological models - force, control, abuse. The ideological view here is that power entails force in its exercise; Power is a means of control, and power can be abused. The model "resources" in the lexical concept "contribution" is selected, and it instantiates three ideological models-hoard, influence, waste. The ideological view is that resources can be hoarded by keeping them away from the people's reach; resources could be used as a means of influencing people's choice and decision, resources could be wasted if not well managed (Figure 2). 
Figure 2. Mapping for '... who Did not Vote for us but Contributed'

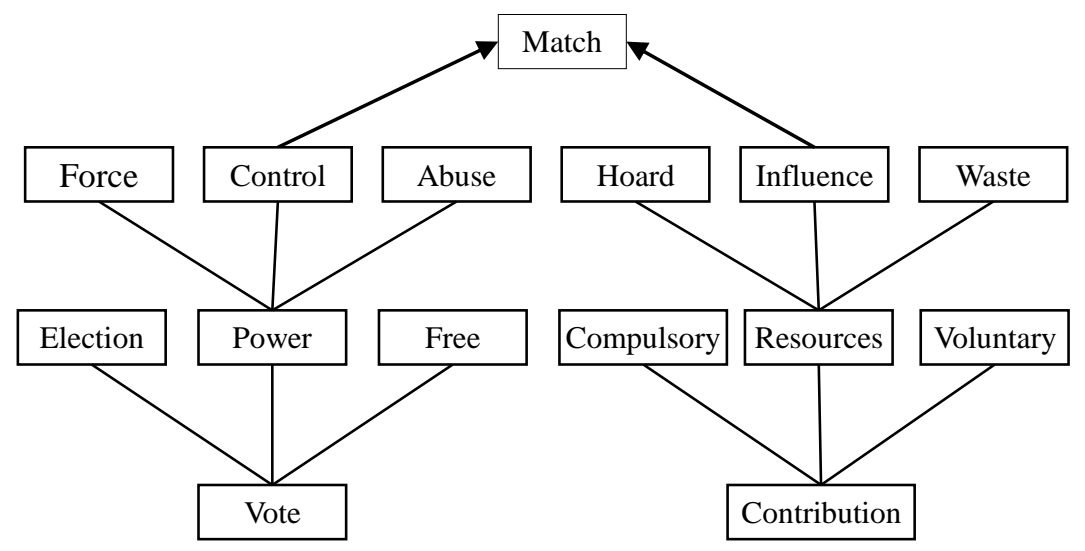

The match takes place between two secondary cognitive models for the lexical concepts, vote and contribution, respectively. The secondary cognitive models, control and influence for the lexical concepts vote and contribution respectively attain schematic coherence which allows matching to take place between the two lexical concepts. The ideological belief expressed in the metaphor is that control, which is one of the interpretations of the lexical concept, vote, is coherent with influence, which is one of the interpretations of the lexical item-contribution. Matching that takes place makes it possible to identify the ideological belief of vote, which is control which connects the ideological belief of contribution, which is influence.

The match explores the interpretation of the two ideological interpretations that connect among other ideological interpretations of the two lexical concepts. Vote is understood as a contribution as a result of control found in it, which shares a semantic potential with influence in the lexical concept, contribution. 


\section{2. ...But Contributed to Make our Democratic Culture Truly Competitive, Strong and Definitive}

The ideological belief expressed in the metaphorical text is that democracy is a culture that is practised by many political societies in the world. Three cognitive models are attributed to this culture (Figure 3).

Figure 3. Partial Cognitive Model for 'Democratic Culture'

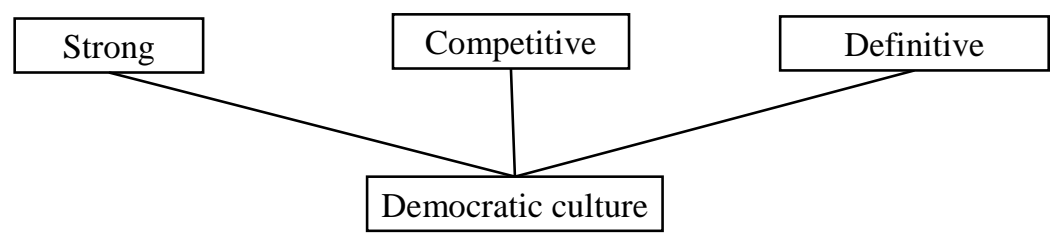

The first is that "democratic culture" is "competitive". The whole democratic process entails competitions among the political actors that show interest in attaining political leadership posts in the society starting with the party primary election to the general election. The instrument or weapon used in that competition is the ability to win the voting power of the electorate. In every democratic state, leadership emerges through electoral competition. The second is "democratic culture" is strong. It is an established culture that is protected by laws and principles. It has a well established process which must be well observed by the participant in the electoral process. Any attempt by any political actors competing in an election to violate the principles guiding the conduct of an election can lead to forfeiture of the candidacy of such of such political actors. Democratic culture is strongly backed up by legal institutions in the nation. The third is "democratic culture" is definitive. Democratic 
culture has been described as the best way through which a society enables the people to choose their representatives in government through their electoral power. The same process could be used to impeach anyone in government that becomes unpopular by not representing the interest of the people that elected him to represent them. Democracy is referred to as the best system of government in the world because it avoids dictatorial tendency by vesting power in the people of the state. It is, therefore, seen as being definitive.

\subsection{These Fears are Groundless}

The ideological belief expressed in text "these fears are groundless" is that fear and groundless are the two lexical concepts with cognitive models that express the understanding of fear in terms of groundless. The lexical concept, fear, instantiates three ideological models - fright, uncertain, worry - at the primary level. The ideological view is that fear causes fright; fear is uncertain, and fear is evident through worry. The lexical concept, groundless, instantiates three ideological models-unfounded, baseless, false. The ideological view expressed is that whatever is ungrounded is unfounded; it is baseless and false, meaning that groundless is unreliable. Therefore, whatever is groundless should not be associated with.

Matching takes place between two models in the cognitive model profiles for "fear" and "groundless" respectively. The cognitive model, uncertain, in the cognitive model profile for the lexical concept "fear" has the possibility of sharing semantic potential with the cognitive model, baseless, in the cognitive model profile for the lexical concept "groundless". The two models in the lexical concepts - fear and groundless - that could be matched in order to the understanding of fear as groundless clear are uncertain and 
baseless (Figure 4).

Figure 4. Mapping for 'These Fears are Groundless'

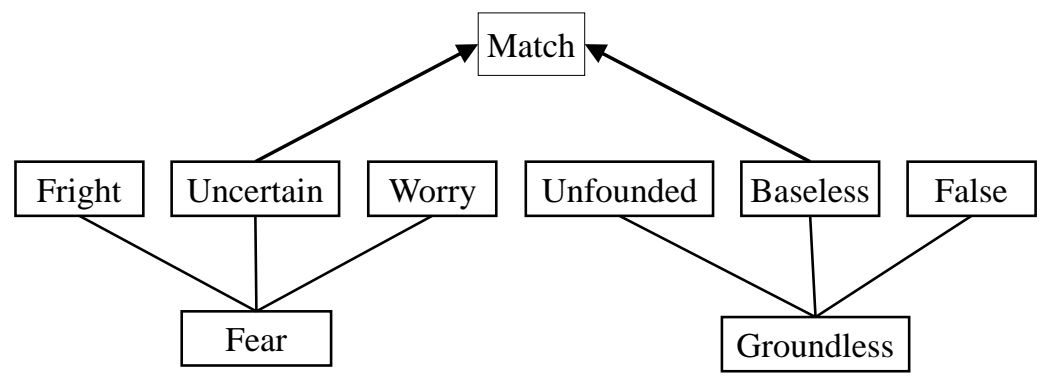

The match takes place between two primary cognitive models for the lexical concepts-fear and groundless. The primary cognitive models - uncertain and baseless - of the lexical concepts - fear and groundless - respectively attain schematic coherence which allows matching to take place between the two lexical concepts. The ideological belief expressed in the metaphor is that uncertain, which is one of the interpretations of the lexical concept, fear, is coherent with baseless, which is one of the interpretations of the lexical concept, groundless. Matching that takes place makes it possible to identify the ideological belief of fear, which is uncertain which connects the ideological belief of groundless, which is baseless. The match explores the interpretation of the two ideological interpretations that connect among other ideological interpretations of the two lexical concepts.

\subsection{The Past is Prologue}

The ideological belief expressed in the text, the past is prologue, is that past and prologue are the two lexical concepts with cognitive 
models that express the understanding of past in terms prologue. The lexical concept, past, instantiates three ideological modelsexperience, former, record - at the primary level. The ideological view is that past events constitute the experience that guide someone's activities in the future; past refers to former activities and events, and past provides records of events for future references. Records from past activities create experience that guides in decision and policy making for a peaceful political atmosphere. The lexical concept, prologue, instantiates three ideological model—introduction, preamble, background - at the primary level. The ideological view expressed is that prologue serves as an introduction to a dramatic event that is complex and complicated; prologue is also a preamble to the main event, and prologue provides background information to a serious discourse (Figure 5).

Figure 5. Mapping for 'The Past is Prologue'

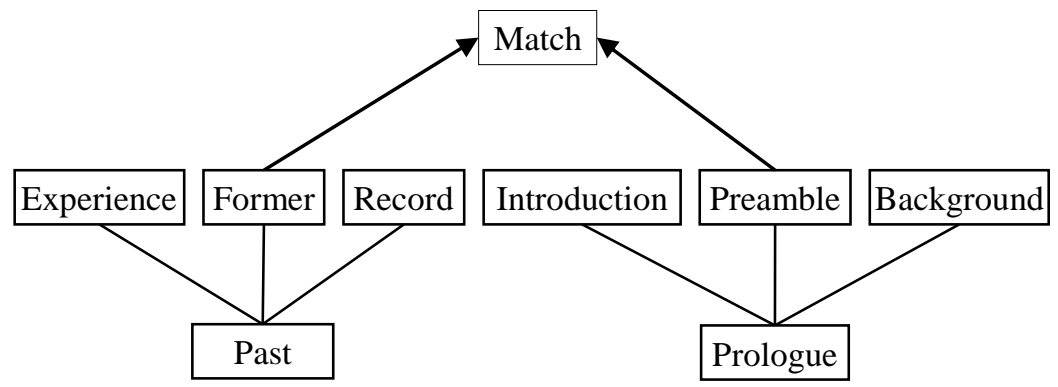

Matching takes place between two primary cognitive models for the lexical concepts-past and prologue. The primary cognitive models - former and preamble - of the lexical concepts - past and prologue-respectively attain schematic coherence which allows matching to take place between the two lexical concepts. The ideological belief expressed in the metaphor is that former, which is 
one of the interpretations of the lexical concept, past, is coherent with preamble, which is one of the interpretations of the lexical concept, prologue. Matching that takes place makes it possible to identify the ideological belief of past, which is former which connects the ideological belief of prologue, which is preamble. The match explores the interpretation of the two ideological interpretations that connect among other interpretations of the two lexical concepts.

\subsection{What is Now Required is to Build on these Legacies}

The ideological belief expressed in the text, "What is now required is to build on these legacies" building and legacy are lexical concepts with cognitive models that express understanding of legacy in form of a building. The lexical concept, building, instantiates three ideological models - foundation, development, maintenanceat the primary level. The ideological view is that building needs a strong foundation to stand on; building must be developed appropriately with quality materials, and building needs proper maintenance to sustain it. The lexical concept, legacy, instantiates three ideological models - source, achievement, sustenance - at the primary level. The ideological view is that legacy has a source where it emanates from; legacy is built on achievements either of an individual or family or society, and legacy needs to be sustained not to lose its relevance.

Matching could not take place at the primary level because the models appropriate for matching could not be identified in cognitive model profiles of the two lexical concepts at the primary level. Therefore, there is a need to initiate a secondary cognitive model profile for a model in each of the two concepts. The model, development, in the lexical concept, building, is selected, and it 
instantiates three ideological models-restructure, renovation, enlargement. The ideological view here is that development could cause restructuring of an existing structure; development necessitates renovation in order to improve the quality and value of existing structure, and development could lead to enlargement of existing structure to accommodate invention and innovation. The model, achievement, in the lexical concept, legacy, is selected and it instantiates three ideological models-preservation, improvement, destruction. The ideological view is that achievement could be preserved and protected; achievement could be improved upon to make it better, and achievement could be destroyed. These ideological views reveal that achievement is not sacrosanct (Figure 6).

Figure 6. Mapping for 'What is Now Required is to Build on these Legacies'

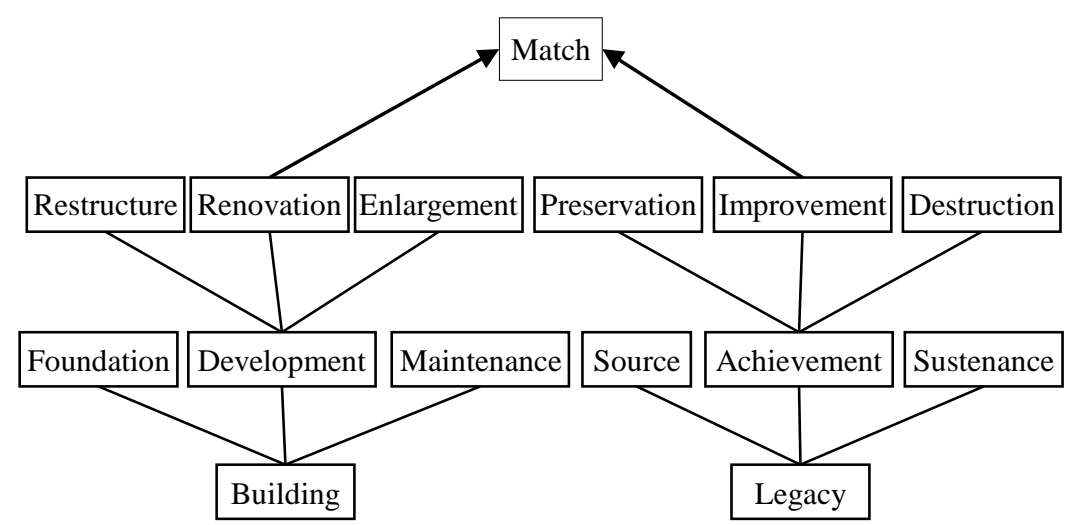

Matching takes place between two secondary cognitive models for the lexical concepts, building and legacy, respectively. The secondary cognitive models, renovation and improvement, for the lexical concepts, building and legacy respectively attain schematic 
coherence which allows matching to take place between the two lexical concepts. The ideological belief expressed in the metaphor is that renovation, which is one of the interpretations of the lexical concept, building, is coherent with improvement, which is one of the interpretations of the lexical concept, legacy. Matching that takes place makes it possible to identify the ideological belief of building, which is renovation, which connects with the ideological belief of legacy, which is improvement.

The match explores the interpretation of the two ideological interpretations that connect among other ideological interpretations of the two lexical concepts. Legacy is interpreted and understood as a building as a result of improvement found in it which share semantic potential with renovation in the lexical concept, building.

\subsection{Our Chosen Route to National Development is Democracy}

The ideological belief expressed in the text "our chosen route to national development is democracy" is that route and democracy are lexical concepts with cognitive models that express understanding of democracy in form of route. The lexical concept, route, instantiates three ideological models - transportation, movement, traveller - at the primary level. The ideological view is that route is essential for transportation; route paves ground for movement to take place, and route is essential for travellers to move from one location to another. The lexical concept, democracy, instantiates three ideological models - people, election, government — at the primary level. The ideological view is that democracy is practised by people to choose their representatives into leadership posts; democracy is practised through election, and democracy is a system of government.

Matching could not be done at the primary level because the appropriate models justifiable for matching could not be identified at 
this level. Therefore, there is a need to initiate a secondary cognitive model profile for a model in each of the two lexical concepts. The model, movement, in the lexical concept, route, is selected, and it instantiates three ideological models - speed, direction, vehicle. The ideological view is that movement is measured by speed, the faster the speed: the faster the movement; movement is guided by direction because movement without direction leads to a wrong destination, and vehicle is a means of movement. The model, election, in the lexical concept, democracy, is selected, and it instantiates three ideological models - candidate, process, voter. The ideological view is that there must be candidates vying for political posts before an election can take place; a lot of processes are involved in election, and voters must cast their vote in an election. It is the vote of the voters that determines the winner in an election (Figure 7).

Figure 7. Mapping for 'Our Chosen Route to National Development is Democracy'

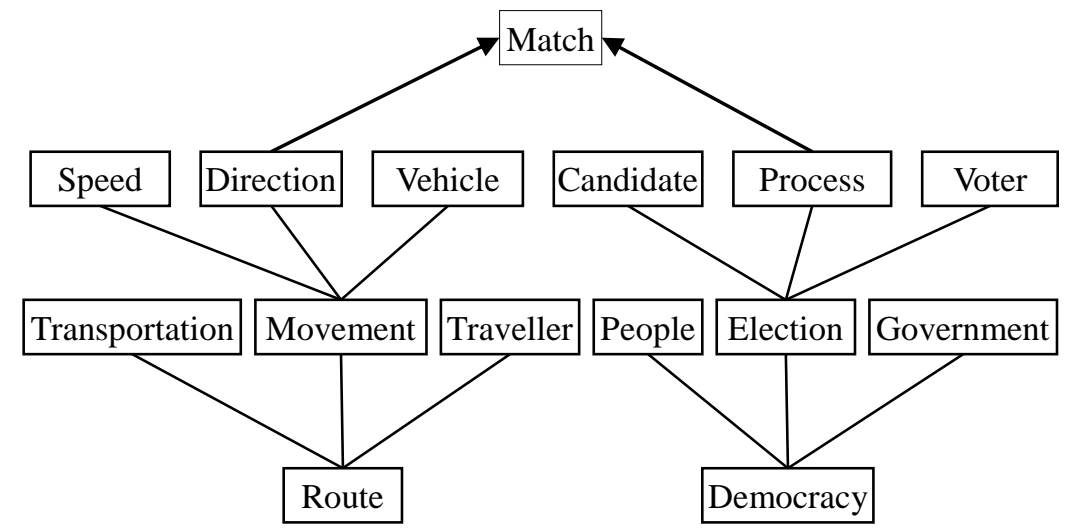

Matching takes place between two secondary cognitive models for the lexical concepts, route and democracy, respectively. The 
secondary cognitive models, movement and election, for the lexical concepts, route and democracy respectively, attain schematic coherence which enables matching to take place between the two lexical concepts. The ideological belief expressed in the metaphor is that direction which is one of the interpretations of the lexical concept, route, is coherent with process which is one of the interpretations of the lexical concept, democracy. The match makes it possible to identify the ideological belief of route, which is direction, which connects the ideological belief of democracy, which is process.

The match explores the interpretation of the two ideological interpretations that connect among other ideological interpretations of the two lexical concepts. Democracy is understood as route as a result of process found in it, which shares semantic potential direction in the lexical concept route.

\subsection{The Federal Government should not Fold its Arms and Close its Eyes}

The ideological belief in the metaphorical text "the federal government should not fold its arms and close its eyes" is that the federal government has eyes and arms. These are the cognitive models attributed to this level of government. The first is that the federal government has arms with which it operates. The arm instantiates three ideological models-legislature, executive, judiciary - in its cognitive model profile. The legislative arm of government is responsible for making laws and policies that regulate the affairs of the state. The legislative body is saddled with the responsibilities of making laws that defend the government and the country against negative foreign and local influences. It also makes laws that move the government and the country forward. The 
executive arm is responsible for the implementation and enforcement of the policies and laws made by the legislative arm. The executive makes the citizens feel the impact of the government. The judicial arm helps in interpretation and application of law into individual cases. This arm helps the government to settle individual and communal grievances through interpretation and application of the meaning of law to the cases in the court of law. The ideological view of the arm of government is that the arm of government is strong and effective enough to achieve its goals, defend its territories and compel obedience.

The second is that the federal government has eyes which serve as its representatives in the country. The eye instantiates three models - ministry, agency, parastatal-in its cognitive model profile. Ministries are established by the government as its eye, and the ministers in the ministries are there to run the ministries as the representatives of the federal government. The major issues that concern the country as a whole or in part are discussed at the ministry that the issue related to, and the decision of the head of the ministry is binding as the decision of the government. The presidency gets the information of the events happening in the country through the ministries. Agencies are set up as the eye of the federal government to carry out particular tasks with executive power. They monitor events and activities of different organisations on behalf of the government. The federal government creates parastatals as its eye to indicate its interest in the economic activities going on in the country and monitor the economical standard of the country (Figure 8). 
Figure 8. Partial Cognitive Model for 'The Federal Government should not Fold its Arms and Close its Eyes'.

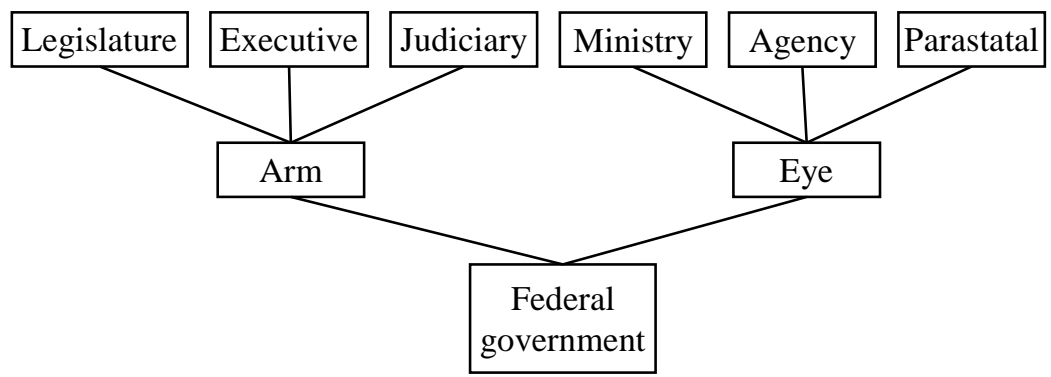

The ideological belief in the metaphorical text is that the government is effective in handling the affairs of the country because it has functional metaphorical arms and eyes which are used in handling all the administration of the country and ensure a smooth running of all its activities. The arm has three ideological interpretations-legislature, executive, judiciary — which are needed to understand the meaning of government. Every form of government possesses these three arms. The eye also has three ideological beliefs - ministry, agency, parastatal. These represent government in the country by handling various tasks and duties needed.

\section{Discussion}

Having recognised and identified the use of metaphorical text in political discourse using President Muhammadu Buhari's inaugural speech as data, the importance of metaphor in the composition of social discourse is realised through the analysis of the text. Findings from the study are discussed below. 
Figurative language, especially metaphor, is crucial in political discourse for codification of ideological belief that necessitates effective and successful administration of a nation. The ideological beliefs encoded in the text are explored in a taxonomic relationship between two lexical concepts in the text by probing into their cognitive model profiles to identify the cognitive models appropriate for realisation of the ideological belief.

In 'I thank our other countrymen and women who did not vote for us but contributed', the ideological belief is that voting is a form of contribution towards governing a nation. The voting could be for or against a government based on the conviction of the voter. It is believed that not only those who voted in an election for a government that contributed to the success of that government. Those who did not vote at all or voted against the government also made their own contribution.

In 'but contributed to make our democratic culture truly competitive, strong and definitive', the ideological belief is that democracy is a culture that is highly competitive, very strong and definitive. The culture of democracy is characterised with electoral competition where candidates strive to have the highest number of votes in order to emerge as the winner. This culture is strongly backed by the constitution and declared as the best form of government.

In 'these fears are groundless', the ideological belief is to see fear as being groundless and inconsequential. It is uncertain and baseless as demonstrated in the analysis. So, fear should not be given room in governing a nation. Government should act without fear.

In 'the past is prologue', the ideological belief is that past activities, events, achievements and failures serve as prologue for future decisions and events. Past mistakes and failures should be 
avoided while past success and achievements should be built upon.

In 'what is now required is to build on these legacies', the ideological belief is that legacy should be understood as a building which requires process and time to complete. Even when it is completed, it could still be improved upon through renovation. Legacy is not what someone achieves overnight; it is achieved through various valuable activities and diligence. At any stage of achievement, legacy could still be improved upon.

In 'our chosen route to national development is democracy', the ideological belief is that democracy is understood as a route to national development. Democracy is seen as an avenue through which people choose their representatives to political offices to represent their interest. Therefore, democracy is not the destination but route through which good government that would lead to national development could be achieved.

In 'the federal government should not fold its arms and close its eyes', the ideological belief is that the federal government has arms through which it regulates and govern the nation. The legislative, executive and judicial arms of government are instrumental to effective governing of the country. The eyes of government are ministries, agencies and parastatals that represent government in the society to achieve national goals.

Another finding is that interpretation of ideological views in the metaphorical text contributes towards cognition of the metaphors in political discourse. Each of the metaphorical texts has ideological views which are revealed through cognitive model profiles of the lexical concepts selected for matching both at the primary and secondary levels. The ideological views contribute towards cognition of the metaphors in the following.

In 'I thank our other countrymen and women who did not vote for 
138 Cognition of Metaphorical Text in President Muhammadu Buhari's

us but contributed', the ideological views at the primary level are 'voting is a process of election; voting stands as the power of electorate to choose their representatives, and voting should be free and fair'; 'contribution may be compulsory, where every member of a group is compelled to make contributions; contribution provides resources-either financial or material or human - that are essential for any successful administration, and contribution could be voluntary, where the contributors willingly make their contributions without being coerced'. The ideological views at the secondary level are 'power entails force in its exercise; power is a means of control, and power can be abused'; 'resources can be hoarded by keeping them away from the people's reach; resources could be used as a means of influencing people's choice and decision, resources could be wasted if not well managed'. These ideological views contribute towards cognition of metaphorical text which is 'voting is a contribution to governance'.

In 'but contributed to make our democratic culture truly competitive, strong and definitive', the ideological view is that 'political process entails competitions among political actors; democratic culture is backed up by legal institutions in the nation, and democratic culture is definitive because it is referred to as the best system of government.' This view, by implication, helps in cognition of democratic culture.

In 'these fears are groundless', the ideological views are 'fear causes fright; fear is uncertain, and fear is evident through worry'; 'whatever is ungrounded is unfounded; it is baseless and false, meaning that groundless is unreliable'. These views aid cognition of fear as groundless.

In 'the past is prologue', the ideological views are 'past events constitute the experience that guide someone's activities in the 
future; past refers to former activities and events, and past provides records of events for future references'; 'prologue serves as an introduction to a dramatic event that is complex and complicated; prologue is also a preamble to the main event, and prologue provides background information to a serious discourse'. The views contribute to the understanding of past as prologue.

In 'what is now required is to build on these legacies', the ideological views at the primary level are 'building needs a strong foundation to stand on; building must be developed appropriately with quality materials, and building needs proper maintenance to sustain it'; 'legacy has a source where it emanates from; legacy is built on achievements either of an individual or family or society, and legacy needs to be sustained not to lose its relevance'. The ideological views at the secondary level are 'development could cause restructuring of an existing structure; development necessitates renovation in order to improve the quality and value of existing structure, and development could lead to enlargement of existing structure to accommodate invention and innovation'; 'achievement could be preserved and protected; achievement could be improved upon to make it better, and achievement could be destroyed'. These views make understanding of legacy as building clear.

In 'our chosen route to national development is democracy', the ideological views at the primary level are 'route is essential for transportation; route paves ground for movement to take place, and route is essential for travellers to move from one location to another'; 'democracy is practised by people to choose their representatives into leadership posts; democracy is practised through election, and democracy is a system of government'. The ideological views at the secondary level are 'movement is measured by speed, the faster the speed: the faster the movement; movement is 
guided by direction because movement without direction leads to a wrong destination, and vehicle is a means of movement'; 'there must be candidates vying for political posts before an election can take place; a lot of processes are involved in election, and voters must cast their vote in an election'. These views aid cognition of democracy as a route.

In 'the federal government should notfold its arms and close its eyes', the ideological views are 'the arm of government is strong and effective enough to achieve its goals, defend its territories and compel obedience'; 'the eye of government is sharp and clear enough to see everything that is going on in the society'. These views justify the interpretation of the arms and eyes of the federal government.

It has been proven that metaphor is an embodiment of ideologies as different ideological views could be generated from the lexical concepts selected in a metaphorical text to generate models for matching. If another model is selected from the cognitive model profile of each of the two lexical concepts selected, another ideological belief would be generated different from the one that was generated. For example, if the models abuse and waste are selected for matching from the secondary cognitive model profiles of the lexical concepts vote and contribution in the metaphorical text 'who did not vote but contributed', another ideological belief which is a different interpretation of the metaphor would be generated.

The relationship between the linguistic content of the metaphorical texts contributes towards their interpretation. The lexical items selected for the desired interpretation are in consonance with grammatical items in the metaphorical text. The lexical items selected have some internal linguistic properties which are explored to discover the required interpretation of the metaphor. 
As demonstrated, metaphors in Nigerian political discourse address contemporary political issues in Nigeria. The president admitted that not all Nigerians voted him, and he tried to appeal to their consciousness to support his government. $\mathrm{He}$ also acknowledged the strength of democratic culture in Nigeria as being competitive, strong and definitive because he had just moved a sitting president of the country out of office through an election. The importance of the success and failure of the past government was acknowledged as a guide to making decisions and policies that would move the country forward. The need for national development which is a crucial issue in Nigeria was brought to the fore through metaphorical text in the speech.

\section{Conclusion}

Cognition of metaphors in political discourse has been explored in this paper applying LCCM theory to President Muhammadu Buhari's inaugural speech. The study has shown that figurative language, especially metaphor, is crucial in the composition of political discourse for conceptualisation of political ideologies that shape the social structure and help in the coordination of effective governance. Cognition of metaphorical text entails understanding socio-cultural and political context that necessitates emergence of the discourse, and also taking socio-cultural cognitive ability of the audience into consideration because these would help in realisation of the required meaning appropriate to the socio-political context. Every metaphorical text has potential of projecting different interpretations which may cause complication of meaning, but cognitive model profile provides various options to choose from in 
142 Cognition of Metaphorical Text in President Muhammadu Buhari's

order to understand a particular ideological belief.

\section{References}

Bayram, F. 2010. Ideology and Political Discourse: A Critical Discourse Analysis of Erdogan's Political Speech. Annual Review of Education, Communication \& Language Sciences 7 , 23-40.

Beard, A. 2000. The Language of Politics. London: Routledge. Boubekri, A. 2019. Conditionals in Moroccan Arabic. Journal of Universal Language 20.1, 1-38 (https://doi.org/10.22425/jul. 2019.20.1.1).

Buhari, M. 2015. President Buhari's Inaugural Speech on May 29, 2015. The Guardian. Available at <https://m.guardian.ng/features/ president-muhammadu-buharis-inaugural-speech/amp/\#top>.

van Dijk, T. 1997. What is Political Discourse Analysis? In J. Blommaert \& C. Bulcaen (eds.), Political Linguistics. Amsterdam: Benjamin.

van Dijk, T. 2008. Discourse and Context: A Sociocognitive Approach. Cambridge: CUP.

Edelman, M. 1977. Political Language: Words that Succeed and Policies that Fail. New York: Academic Press.

Evans, V. 2006. Lexical Concepts, Cognitive Models and Meaning Construction. Cognitive Linguistics 17.4, 491-534 (https://doi. org/10.1515/COG.2006.016).

Evans, V. 2009a. How Words Mean: Lexical Concepts, Cognitive Models and Meaning Construction. Oxford: OUP.

Evans, V. 2009b. Semantic Representation in LCCM Theory. In V.

Evans \& S. Pourcel (eds.), New Directions in Cognitive 
Linguistics 27-55. Amsterdam: John Benjamins.

Evans, V. 2010a. Figurative Language Understanding in LCCM Theory. Cognitive Linguistics 21.4, 601-662 (https://doi.org/ 10.1515/cogl.2010.020).

Evans, V. 2010b. From the Spatial to the Non-spatial: The 'State' Lexical Concepts of in, on and at. In V. Evans \& P. Chilton (eds.), Language, Cognition and Space: The State of the Art and New Directions 215-248. London: Equinox.

Evans, V. 2013a. Language and Time. Cambridge: CUP.

Evans, V. 2013b. Metaphor, Lexical Concepts, and Figurative Meaning Construction. Journal of Cognitive Semiotics 5.1-2, 73-107 (https://doi.org/10.1515/COGSEM.2009.5.12.73).

Fromkin, V. et al. 2003. An Introduction to Language. 7th edition. Boston, MA: Wadsworth.

Hernández, R. 2009. The Effect of Language and Context Variability on the Translation of Literary Postcolonial Discourse in Portuguese. Journal of Language and Translation (Now called Journal of Universal Language) 10.2, 57-85 (https://doi.org/ 10.22425/jul.2009.10.2.57).

Johnson, D. \& R. Johnson. 2000. Civil Political Discourse in a Democracy: The Contribution of Psychology. Peace and Conflict: Journal of Peace Psychology 6.4, 291-317 (https://doi.org/ 10.1207/S15327949PAC0604_01).

Lakoff, G. \& M. Johnson. 1980. Metaphors We Live By. Chicago, IL: University of Chicago Press.

Müller, R. 2005. Creative Metaphors in Political Discourse. Theoretical Consideration on the Basis of Swiss Speeches. Metaphorik De 9, 53-73.

Opeibi, B. 2005. Sense and Meaning in Campaign Texts: A Study of Cohesion in Nigerian Political Discourse. Gegee: Ogun Studies in English 5.1, 116-204. 
144 Cognition of Metaphorical Text in President Muhammadu Buhari's

Opeibi, T. 2007. Language Politics and Democratic Governance in

Nigeria: A Sociolinguistic Perspective. In G. Samuel (ed.), Issues in Political Discourse Analysis II. New York: Nova Science.

Opeibi, T. 2009. Discourse, Politics and the 1993 Presidential Election Campaigns in Nigeria. Ibadan: Straight Gate.

Opeibi, T. 2018. Gaining Political Capital through Social Media: A Study of Akinwunmi Ambode's Twitter Campaigns during the 2015 Election in Nigeria. In T. Opeibi \& J. Schmied (eds.), Research in English and Applied Linguistics REAL XIII 1-30. Göttingen: Cuvillier Verlag.

Osoba, J. 2014. The Use of Nigerian Pidgin in Political Jingles. Journal of Universal Language 15.1, 105-127 (https://doi.org/ 10.22425/jul.2014.15.1.105).

Osoba, J. 2018. Powerin Nigerian Pidgin (NP) Discourse. Journal of Universal Language 19.1, 1-32 (https://doi.org/10.22425/jul. 2018.19.1.1).

Park, O. 2009. The Issue of Metaphor in Literary Translation: Focusing on the Analysis of a Short Story Translation. Journal of Language and Translation (Now called Journal of Universal Language) 10.1, 155-175 (https://doi.org/10.22425/jul.2009.10. 1.155).

Salamini, L. 1981. The Sociology of Political Praxis. An Introduction to Gramsci's Theory. London: Routledge.

Sobola, E. 2013. Argumentative Patterns in President Goodluck Jonathan's Inaugural Speech. Lagos Notes and Record 19.1, 123-146.

Sobola, E. 2019. Meaning in Metaphors Used in Nollywood Films:

A Lexical Concept Integration. Journal of Universal Language 20.1, 99-126 (https://doi.org/10.22425/jul.2019.20.1.99).

Solomon-Etefia, P. 2018. Pragmemesin Outdoor HIV/AIDS 
Campaign Messages in Benin Metropolis, Nigeria. Journal of Universal Language 19.1, 85-114 (https://doi.org/10.22425/jul. 2018.19.1.85).

Wilson, J. 2001. Political Discourse. In D. Schiffrin et al. (eds.), Handbook of Discourse Analysis 775-794. London: Blackwell. 